\title{
Group Purchase Strategy Research Based on Channel Game
}

\author{
Xuyao Lin \\ Department of Business Administration \\ Fujian Jiangxia University \\ Fuzhou, China \\ 21901616@qq.com
}

\begin{abstract}
The choice of the transaction mode is the result of buyers and sellers' game. Whether the group purchase transactions can exist and be developed well depend on whether the earnings of buyers and sellers can be effectively balanced. The conditions which form the stable group purchase transaction can be found through the earnings analysis of the both parties to the transaction. And then the corresponding strategy will be proposed accordingly, so as to improve the efficiency of group purchase transactions.
\end{abstract}

Keywords-group purchase;channel choice; game theory;

\section{FOREWORD}

In recent years, the network group purchase as a new ecommerce mode is growing up rapidly with the development of the Internet. In November 2008, the American group purchase website Groupon launched a new network group purchase mode, and then the enthusiasm for network group purchase is very popular in the field of electronic commerce. Groupon network group purchase mode was introduced into China at the end of 2009. The domestic group purchase websites have been increased to more than 5000 and the market sales have been reached 1.2 billion since two years ago. The goods and service they launched cover all the aspects of people life, including catering, entertainment, beauty, clothing shoes and hats, digital home appliances, furniture and appliance and so on. However, in the second half of 2011, the network group purchase which has quickly been developed began to decline. A lot of small and medium sized group purchase websites were forced to close. It is difficult for most of the group purchase websites with good sales to extricate themselves due to the deep loss. The netizens are not satisfied with the goods and service provided by the group purchase websites. The investigation shows the netizens don't sing high praise for the goods and service provided by the group purchase websites overall. Only $16.16 \%$ of the respondents regard it as "satisfied" while more than $80 \%$ of them regard it as "general" or "not satisfied". The reputation of the whole network group purchase is seriously affected. The network group purchase as a new consumption life pattern is being challenged as well.

\section{GROUP PURCHASE OVERVIEW}

"Group purchase is shopping by groups. It refers to a shopping way in which customers knowing or not knowing each other unite to improve the business negotiation skills so that they can obtain the optimal price."[1] From the transaction perspective, many customers unite together can enhance the bargain ability between the customers and sellers. They can get the discounts to great extent and then get the needed goods and service by the optimal price. For the sellers, they can sell better via promotion. The more profit can be got by "small profits and quick returns".

The domestic group purchase came into being in the 1980's. Initially some of the units and groups buy some household items together. Then some individuals organized spontaneously to purchase some particular product or service so that they can obtain some discount. It can be seen that as a commercial transaction mode, group purchase is nothing new. But the ex group-purchase developed very slowly before the e-commerce developed, which was based on the Internet.

As a business mode, the basic characteristics of group purchase can be summarized as: "decentralized decisionmaking, group purchase, separate consumption". That is, customers who participate in group purchase have the power of independent consumption decision-making. And then they can make different consumption decisions according to their own judgements. When trading with sellers, customers emerge as a group. But when goods and service is delivered, sellers are confronted with different customers. The basic characteristics of the group purchase make the group purchase transaction more complex than the traditional trade. At the same time, the transaction time is longer and the there are more segments.

There were some successful cases among group purchase transactions in the early stage. But generally speaking, most of the cases failed. Most of the problems among group purchase transactions in the early stage are: Firstly, the information is seriously asymmetric. The information regarding price and the product quality which the customers can get is very limited, so it is difficult for the customers to make effective comparisons on price and quality and then calculate the cost and benefit in group purchase activities. Therefore, most of consumers don't make decisions before careful consideration. There is a big gap between the customer expectations and the reality during the transaction procedure due to their blind decision. The customer satisfaction is relatively low. Secondly, customers in the group purchase transactions are not an effective organization. The customer group is a temporary group formed by many customers knowing or not knowing each other. The structure of group members is complex. It is difficult for the group to restrict the group members' behavior. The communication between the group members is difficult. The group members 
are difficult to reach a consensus and take an effective common action.

With the rapid development of electronic commerce, as well as the rise of social media based on the Internet, the problem of the information asymmetry between customers and sellers has been solved well. Customers can fully understand the market price and the information of product quality via the electronic commerce websites. And they can make effective price comparisons. They communicate well via the forum, micro-blog and so on, so that they form an effective customer group. Therefore, as a new form which pops up quickly, the network group purchase which is based on the Internet and ecommerce, is drawing more and more sellers and consumers' attention.

\section{Static Game AnAlysis OF The Group PuRChase TRANSACTION}

Either the new network group purchase or the traditional group purchase without network, in spite of their different transaction means, the basic principle and the process are the same. The group purchase transaction mode adds a trading channel for the sellers and customers involved in the transaction. The nature of group purchase transaction decisionmaking is the transaction channel selection. That is, for the sellers, the group purchase adds a sale channel. The sellers can choose the traditional trading mode or group purchase trading mode. For the customers, the group purchase adds a purchase channel. The customers can choose either the traditional trading mode or the group purchase trading mode. There are two problems need to be solved regarding whether the group purchase transactions can become an effective trading channel. One is whether the participating parties would like to choose the group purchase transaction. The other is whether the group purchase transaction can be processed stably. In other words, the group purchase transaction is not an occasional behavior in some specific conditions, but it can become a stable trading mode. The static and dynamic game analysis is used to analyze these two problems as follows.

When selecting the trading channel, the participants know the feature of other participants, the strategy space and the payoff function well. That is, the information is complete, and the actions are taken at the same time in the decision-making process. Thus, the choices of both sides compose a complete information static game. Which trading mode both sides of the transaction are selected depends on the earnings of both parties to the transaction.

\section{Hypothesis:}

- Group purchase is not the only choice of both transaction parties. In case there is no group purchase, both the sellers and buyers can use the traditional way to make a deal.

- Assumed that the participants in the game procedure are all rational economic man, they all pursue the maximum of personal interests in the transaction process.

- Assumed that the information in the game process is complete and perfect, participants can easily obtain the market price of goods or service. Both of the sides understand the possible choices of the other side.
- Assumed under the traditional sale circumstance, the market price of a commodity is $\mathrm{P}$, the cost is $\mathrm{C}$ and the corresponding demand is Q.

- Assumed the income of both traditional transaction sides is the base, that is the income is $(0,0)$. The group purchase transaction earnings relates to traditional trading is $(\Delta \mathrm{U}, \Delta \mathrm{V})$.

- In the group purchase situation, the market price change of a commodity is $\Delta \mathrm{P} . \Delta \mathrm{Q}$ is the change of customer demand and the price elasticity of customer demand for commodities is $\gamma=-(\Delta \mathrm{Q} / \mathrm{Q}) /(\Delta \mathrm{P} / \mathrm{P})$.

Both sides situation in the games are as follows:

customer

\begin{tabular}{|c|c|c|c|}
\hline & & $\begin{array}{c}\text { Group } \\
\text { purchase }\end{array}$ & $\begin{array}{c}\text { Traditional } \\
\text { trading }\end{array}$ \\
\hline & $\begin{array}{c}\text { Group } \\
\text { purchase }\end{array}$ & $\begin{array}{ll} & \Delta \mathrm{V} \\
\Delta \mathrm{U} & \end{array}$ & 0 \\
\hline & $\begin{array}{l}\text { Traditional } \\
\text { trading }\end{array}$ & 0 & 0 \\
\hline
\end{tabular}

The action combination of seller and consumer is (Group purchase, Group purchase), (Traditional trading, Group purchase), (Group purchase, Traditional trading), (Traditional trading, Traditional trading). Since the consumer side is composed of consumer groups, here customers choose "the traditional transaction" refers to the numbers of customers participants in group purchase does not reach the number the group purchase transaction agreeing on. So as long as one side of participants does not select the "group purchase transaction", the group purchase can't be formed. Both sides can only adopt the traditional trading transaction, so their income is zero in the transaction. When both sides choose "group purchase transaction", the group purchase is formed. Compared with the traditional business, the profit of the sellers is $\Delta \mathrm{U}, \Delta \mathrm{V}$ is customer income.

\section{A. Consumers Benefit Analysis}

For the customer, in the case of group purchase, the change of commodity market price is $\Delta \mathrm{P}$, so customers buy the merchandise by price $\mathrm{P}+\Delta \mathrm{P}$. Customer earnings is $\Delta \mathrm{V}=-$ $[(\mathrm{P}+\Delta \mathrm{P}) \cdot(\mathrm{Q}+\Delta \mathrm{Q})-\mathrm{P}(\mathrm{Q}+\Delta \mathrm{Q})]=-\Delta \mathrm{P}(\mathrm{Q}+\Delta \mathrm{Q})$, Where: The negative sign indicates less consumer spending. When $\Delta \mathrm{P}>0$, the customer buy the same commodity by price $\Delta \mathrm{P}$, which is higher than traditional transactions price. So the earnings of the customer participate in the group purchase $\Delta \mathrm{V}$ $<0$; When $\Delta \mathrm{P}<0$, compared with the traditional transaction, the individual customer buy the same commodity by the price which is less than the market price $\Delta \mathrm{P}$, so the earnings of the customer participate in the group purchase $\Delta V>0$. Every customer income is- $\Delta \mathrm{P}$. As customers are rational, when $\Delta \mathrm{V}$ $<0$, customers won't participate in the group purchase. Thus, only when $\Delta \mathrm{P}<0$, the commodity discounted, customers will participate in the group purchase. Otherwise, customers will choose the traditional transaction. 


\section{B. Sellers Benefit Analysis}

For sellers, the market price of a commodity is $\mathrm{P}$, the cost is $\mathrm{C}$, the corresponding market demand is $\mathrm{Q}$, so the sellers profit in traditional trading mode is: $\mathrm{U}=(\mathrm{P}-\mathrm{C}) \mathrm{Q}$. In the group purchase mode, when the price change is $\Delta \mathrm{P}$, the corresponding market demand change is $\Delta \mathrm{Q}$. Sales profit: $\mathrm{U}^{\prime}=$ $(\mathrm{P}+\Delta \mathrm{P}-\mathrm{C}) \cdot(\mathrm{Q}+\Delta \mathrm{Q})$. So: $\Delta \mathrm{U}=\mathrm{U}^{\prime}-\mathrm{U}=(\mathrm{P}+\Delta \mathrm{P}-\mathrm{C}) \cdot(\mathrm{Q}+\Delta \mathrm{Q})-(\mathrm{P}-$ $\mathrm{C}) \cdot \mathrm{Q}=\Delta \mathrm{P} \cdot \mathrm{Q}+(\mathrm{P}-\mathrm{C}) \cdot \Delta \mathrm{Q}+\Delta \mathrm{P} \cdot \Delta \mathrm{Q}$. Because the consumer price elasticity of demand for commodities is $\gamma=-$ $(\Delta \mathrm{Q} / \mathrm{Q}) /(\Delta \mathrm{P} / \mathrm{P}), \quad \Delta \mathrm{Q}=-\gamma \cdot \Delta \mathrm{P} \cdot(\mathrm{Q} / \mathrm{P}) \quad$ and $\quad \Delta \mathrm{U}=\Delta \mathrm{P} \cdot \mathrm{Q}-(\mathrm{P}-$ $\mathrm{C}) \cdot \Delta \mathrm{P} \cdot \gamma \cdot(\mathrm{Q} / \mathrm{P})-\Delta \mathrm{P} 2 \cdot \gamma \cdot(\mathrm{Q} / \mathrm{P})$. Right $\Delta \mathrm{U}$ an order derivative obtained: $\mathrm{d} \Delta \mathrm{U} / \mathrm{d} \Delta \mathrm{P}=\mathrm{Q}-(\mathrm{P}-\mathrm{C}) \cdot \gamma(\mathrm{Q} / \mathrm{P})-2 \cdot \Delta \mathrm{P} \cdot \gamma(\mathrm{Q} / \mathrm{P})$. Make $\mathrm{d}$ $\Delta \mathrm{U} / \mathrm{d} \Delta \mathrm{P}=0$, so $\mathrm{Q}-(\mathrm{P}-\mathrm{C}) \cdot \gamma(\mathrm{Q} / \mathrm{P})-2 \cdot \Delta \mathrm{P} \cdot \gamma(\mathrm{Q} / \mathrm{P})=0$.

The derivation of $\Delta \mathrm{U}$ of order two: $\mathrm{d} 2 \Delta \mathrm{U} / \mathrm{d} \Delta \mathrm{P} 2=-2$. Therefore $\Delta \mathrm{U}$ is a concave upward curve which presents the maximum value. When $\Delta \mathrm{U}=\Delta \mathrm{P} \cdot \mathrm{Q}-(\mathrm{P}-\mathrm{C}) \cdot \Delta \mathrm{P} \cdot \gamma \cdot(\mathrm{Q} / \mathrm{P})-$ $\Delta \mathrm{P} 2 \cdot \gamma \cdot(\mathrm{Q} / \mathrm{P})=0, \quad \Delta \mathrm{P}=0$ or $\Delta \mathrm{P}=\frac{\mathrm{P}-(\mathrm{P}-\mathrm{C}) \cdot \gamma}{\gamma}$. Figure 1 below: when $\Delta \mathrm{P}=\frac{\mathbf{P}-(\mathbf{P}-\mathbf{C}) \cdot \gamma}{\gamma}<0$, it is shown in the solid curve line. When $\Delta \mathrm{P}=\frac{\mathrm{P}-(\mathrm{P}-\mathrm{C}) \cdot \gamma}{\gamma}>0$, it is shown in the broken curve line in FIG1 .

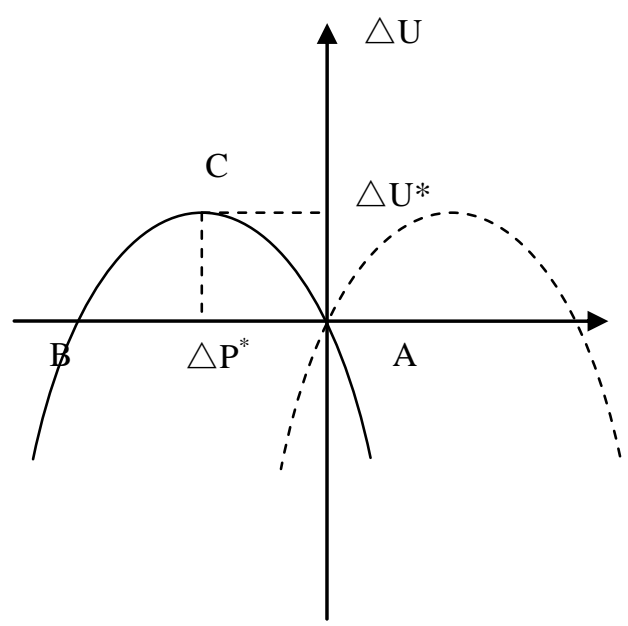

Figure 1

When $\Delta P>0$, it means the sellers raise their selling price. Then customers will not accept the price change and they will choose the traditional trading. The group purchase transactions can not be formed. Therefore, only when $\Delta \mathrm{P} \in\left(\frac{\mathrm{P}-(\mathrm{P}-\mathrm{C}) \cdot \gamma}{\gamma}, 0\right)$, the group purchase transaction can be made. And then, $\Delta \mathrm{V}>0$ and $\Delta \mathrm{U}>0$.

To sum up:

- From the above analysis, only when $\underline{\mathrm{P}-(\mathrm{P}-\mathrm{C}) \cdot \gamma}$

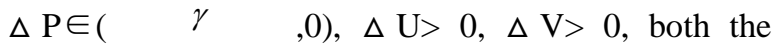
customers and sellers gain positive return. So (participation, involvement) strategy is Nash equilibrium strategy and the group purchase behavior can be formed spontaneously.
- Consumer's income varies linearly. With the discount $(\Delta \mathrm{P})$ increasing, sales increases. So the greater the discount, the higher enthusiasm of the customer group purchase participation.

- The change of the seller earnings. With the discount $(\Delta \mathrm{P})$ increasing, the sales volume $(\Delta \mathrm{Q})$ increases and the income $(\Delta \mathrm{U})$ increases as well. When it reaches point $\mathrm{C}$, the gains is the maximum. When discount $(\Delta$ $\mathrm{P})$ continues to increase, income gradually decreases. When reaching point $\mathrm{B}$, the income is 0 . And the earnings of seller choosing group purchase transaction is the same as the traditional trading.

\section{GROUP PURCHASE STRATEGIC ANALYSIS FOR SELLERS}

\section{A. Product Selection Strategy}

As shown in figure 1: when $\Delta \mathrm{P}=\frac{\mathrm{P}-(\mathrm{P}-\mathrm{C}) \cdot \gamma}{\gamma}<0, \Delta \mathrm{U}$ cross the $\mathrm{X}$-axis $\mathrm{A}(0,0), \mathrm{B}\left(\frac{\mathrm{P}-(\mathrm{P}-\mathrm{C}) \cdot \gamma}{\gamma}, 0\right)$ At this point $\because \triangle \mathrm{P}=\frac{\mathrm{P}-(\mathrm{P}-\mathrm{C}) \cdot \gamma}{\gamma}<0, \quad$ Also $\because \gamma>0 \therefore \mathrm{P}-(\mathrm{P}-\mathrm{C}) \cdot \gamma<0$, $\therefore \frac{P-C}{P} \cdot \gamma>1, \therefore \gamma>\frac{P}{P-C}$ As a solid line curve shown. Similarly, when $\Delta \mathrm{P}=\frac{\mathrm{P}-(\mathrm{P}-\mathrm{C}) \cdot \gamma}{\gamma}>0, \Delta \mathrm{U}$ cross the $\mathrm{X}$-axis A $(0,0), \mathrm{B}\left(\frac{\mathrm{P}-(\mathrm{P}-\mathrm{C}) \cdot \gamma}{\gamma}, 0\right)$ At this point $\because \triangle \mathrm{P}=\frac{\mathrm{P}-(\mathrm{P}-\mathrm{C}) \cdot \gamma}{\gamma}>0$ Also $\because \gamma>0 \therefore$ P-(P-C) $\cdot \gamma>0 \quad, \quad \therefore \frac{P-C}{P} \cdot \gamma<1$, $\therefore 0<\gamma<\frac{P}{P-C}$ Shown as broken line curve in Figure 1 . Therefore, sellers have two choices in terms of deviation from the traditional trading patterns. One is for commodity $\gamma>\frac{P}{P-C}$. Sellers can reduce the price to get higher demand and higher sales profit. The other is for $0<\gamma<\frac{P}{P-C}$. Sellers can increase the price to get higher sales profit.

From the above analysis, the necessary condition to reach the group purchase is $\Delta \mathrm{P}<0$. Then $\gamma>\frac{P}{P-C}$, when $\mathrm{C} \rightarrow 0$, $\mathrm{P}-\mathrm{C} \rightarrow \mathrm{P}, \frac{P}{P-C} \rightarrow 1$, that is $\frac{P}{P-C}>1$. Therefore, the price elasticity of demand for commodities $\gamma>\frac{P}{P-C}>1$ is the necessary condition to form group purchase. Thus, the resilient commodity is more suitable for group purchase transaction. Also $\because \gamma>\frac{P}{P-C} \therefore$ the smaller P-C, the greater $\gamma$. Therefore, the higher margin commodity in the traditional trading is 
suitable for the group purchase. As $\Delta \mathrm{U}^{*}=\frac{[\mathrm{P}-(\mathrm{P}-\mathrm{C}) \cdot \gamma]^{2} \cdot Q}{4 \gamma P}$, $\Delta \mathrm{U} *$ varies linearly with $\mathrm{Q}$, the bigger $\mathrm{Q}$, the bigger $\Delta \mathrm{U}$. It indicates that the bigger demand for commodities, the more extra earnings the group purchase brings to the sellers. Thus, the attraction for the sellers is bigger.

\section{B. Discounts and Sales Volume Selection Strategy}

From the above analysis, when $\Delta \mathrm{P}=\Delta \mathrm{P}^{*}=\frac{\mathrm{P}-(\mathrm{P}-\mathrm{C}) \cdot \gamma}{2 \gamma}$, the maximum value is $\Delta \mathrm{U}^{*}=\frac{[\mathrm{P}-(\mathrm{P}-\mathrm{C}) \cdot \gamma]^{2} \cdot Q}{4 \gamma P}$. The change of seller earnings $\Delta \mathrm{U}$ is divided into two parts. When $\Delta \mathrm{P} \in(\Delta$ $\mathrm{P} *, 0), \Delta \mathrm{U}$ gradually increases as $\Delta \mathrm{P}$ decreases. When $\Delta \mathrm{P} \in\left(\frac{\mathrm{P}-(\mathrm{P}-\mathrm{C}) \cdot \gamma}{\gamma}, \Delta \mathrm{P}^{*}\right), \Delta \mathrm{U}$ gradually decreases as $\Delta \mathrm{P}$ decreases. As for customers, the smaller $\Delta \mathrm{P}$, the more profit the seller given. The greater $\Delta \mathrm{V}$, the greater benefit the customers get. So the sellers won't select any point corresponding to $\Delta \mathrm{P}$ from point $\mathrm{A}$ to point $\mathrm{C}$ as the group purchase discount. They will select a point corresponding to $\Delta$ $\mathrm{P}$ from point $\mathrm{C}$ to point $\mathrm{B}$ as the discount in the group purchase. The best selling price strategy is to choose the price change $\Delta$ $\mathrm{P} *$. At then the highest earnings of the sellers in the group purchase is $\Delta \mathrm{U} *$. Since $\Delta \mathrm{P}$ and $\Delta \mathrm{Q}$ is a one - to - one relationship, $\Delta \mathrm{Q}=-\gamma \cdot \Delta \mathrm{P} \cdot(\mathrm{Q} / \mathrm{P})$, selecting $\Delta \mathrm{P}$, the sales volume of group purchase is $\mathrm{Q}+\Delta \mathrm{Q}$.

When $\Delta \mathrm{P}<\Delta \mathrm{P} *$, the income of group purchase sellers $\Delta \mathrm{U}$ declines. But when $\Delta \mathrm{P}$ decreasing, $\Delta \mathrm{Q}$ is still increasing. Thus, when $\Delta \mathrm{P}<\Delta \mathrm{P} *$, the group purchase transaction still has marketing value for the sellers. That is, the seller can promote the commdity sales via group purchase and improve the impact of the enterprise and the brand awareness, and gain the extra marketing benefit. In particular, when $\Delta \mathrm{P}=$ $\frac{\mathrm{P}-(\mathrm{P}-\mathrm{C}) \cdot \gamma}{\gamma}, \Delta \mathrm{U}=0$, making the comparison with the traditional sales, sellers can get extra marketing benefit without reducing earnings and adding investment. Therefore, group purchase as a new marketing approach is popular among small and micro sized enterprises.

In summary, sellers choosing the discount $\Delta \mathrm{P}$ between point $\mathrm{C}$ to point $\mathrm{B}$, is $\Delta \mathrm{P} \in\left[\frac{\mathrm{P}-(\mathrm{P}-\mathrm{C}) \cdot \gamma}{\gamma}, \frac{\mathrm{P}-(\mathrm{P}-\mathrm{C}) \cdot \gamma}{2 \gamma}\right]$. The corresponding discount $\mathrm{K} \in\left[\frac{1}{\gamma}+\frac{C}{P}, \frac{1}{2}+\frac{1}{2 \gamma}+\frac{C}{2 P}\right]$, thus the main factor affecting the sellers price and the selection of sales volume is the price elasticity of demand for the commodities $\gamma$ and the gross margin. The greater $\gamma$, the greater the price elasticity of demand for commodities, the greater price discounts the seller can provided with. The higher the gross margin, the greater price discount the sellers can provided with. Selecting $\Delta \mathrm{P}$ depends on the purpose why the sellers take part in the group purchase.

\section{CONCLUSIONS}

The conclusions can be drawn in views of the above analysis:

- It can be known from the static game analysis that the group purchase transaction is a win-win deal both for the sellers and the customers. Compared to the traditional trading, under certain conditions, both the sellers and consumers can get extra earnings in the group purchase transaction. Therefore, the group purchase transaction behavior is relatively stable and it has its inherent vitality. Accordingly, group purchase transaction provides both the customers and the sellers a new and stable trading channel other than the traditional trading.

- It can be shown that only the resilient commodity with higher profit is suitable for group purchase transaction. Meanwhile, the greater elasticity, the higher profit margins of goods, and the greater discount the sellers can give. And more and more customers' attention can be drawn. The sellers should select the right trading channel, make the proper group purchase planning according to the characteristics of their products, so that both of the parties can achieve win-win.

- Group purchase is not only a profitable way, but also a marketing approach. Rational use and the proper the group purchase decision-making can bring the sellers not only extra economical but also marketing benefit. The seller should make the corresponding group purchase strategy to achieve the maximization of the corporate interest according to their own characteristics and strategic objectives.

\section{REFERENCES}

[1] "Group purchase". <http://baike.baidu.com/view/16979.htm.>.

[2] FeiXiaoyan." Network group-research based on game theory".Contemporary Economics.2011,(07):110-112.

[3] Gefen D."Reflections on The Dimensions of Trust And Trustworthiness Among Online Consumers".Database for Ad-vances in Information Systems.2005,33 ( 3 ): 38 .

[4] Zhang weiying,Game theory and information economics,Shanghai:Shanghai people's publishing house,2004.

[5] Kauffman,R.J. and Wang,B., New Buyers'Arrival under Dynamic Pricing Market Microstructure:The Case of Group-Buying Discounts on the Internet,Journal of Management Information System,2001 